\title{
Ramsar Convention and the Wise Use of Wetlands: Rethinking Inclusion ${ }^{\circ}$
}

\author{
Deepa Joshi, Bryce Gallant, Arunima Hakhu, Sanjiv De Silva, Cynthia McDougall, \\ Mark Dubois and Indika Arulingam
}

\begin{abstract}
The Ramsar Convention on Wetlands emphasizes the "wise use" of wetlands by conserving the ecological character of wetlands while managing the socio-economic value these landscapes hold for different stakeholders. Reviewing the Convention obligations, resolutions, and guidelines through a feminist political ecology lens, we find them to be overtly simplistic and technocratic. A deliberately generic framing of socio-ecological interrelations and of economic trade-offs between wetland uses and users obscures broader political and social contexts which shape complex nature-society interrelations in the use, management, and governance of wetlands. Poverty, the cultural significance of wetlands-particularly for indigenous communities - and gender equality have only recently been considered in wetlands management and governance guidelines and interventions. These recent additions provide little insight on the power imbalances which shape plural values, meanings, experiences, and voices in wetlands use and governance, especially for the most marginalized of wetlands users. We welcome the call for a "reformulation" of a socio-ecological approach to managing and governing wetlands, but caution that unless wetlands governance structures and processes are re-politicized, changes in policies and approaches will likely remain rhetorical.
\end{abstract}

$\mathrm{T}$ he Ramsar Convention (RC or Convention hereafter) was created in 1971 as an intergovernmental treaty to provide a framework for the sustainable management and governance of wetlands. Kumar et al. (2020; A) point out that "the term, 'wise use' of wetlands, coined then, in an era when protection and the exclusion of human activity dominated conservation thinking and before the 1992 Rio Conference embedded sustainable development into our lexicon, wise use was farsighted in recognising the need to integrate human dimensions in wetland management".

Since 1975, the RC works with national governments to enhance the network of Ramsar Sites and other protected wetland areas to integrate wetlands planning and management into the post-2015 development agenda, to strengthen legal and policy arrangements at scale to conserve all wetlands, to implement Ramsar guidelines for the 'wise use' of wetlands, to enable economic and financial incentives to wetlands conservation for local communities

D This open access article is distributed under the terms of the CC-BYNC-ND license (http://creativecommons.org/licenses/by-nc-nd/3.0) and is freely available online at: http://er.uwpress.org

Ecological Restoration Vol. 39, Nos. 1-2, 2021

ISSN 1522-4740 E-ISSN 1543-4079

(O2021 by the Board of Regents of the University of Wisconsin System. and businesses, to ensure participation of all stakeholders in wetland management, and to improve wetland inventories and tracking at scale (Ramsar Convention Secretariat, 2018b). One hundred and seventy countries are currently signatory to the Convention and over 2,300 diverse wetlands are formally recognized Ramsar sites of International Importance, covering nearly 250 million hectares (ibid).

These agreements and commitments are significant, commendable achievements. Unfortunately, there is increasing concern, that these policies have failed to decrease the destruction and degradation of wetlands globally (Kumar et al. 2020). In 2018, an internal review of the RC reported that "where data is available, 35 percent of wetlands have been lost since 1970, at a rate three times greater than that of forests" (Ramsar Convention Secretariat, 2018b; 2). Kumar et al. (2020) call for a strategic "reformulation" arguing that what needs changing is the dominance of the ecological framing of wetlands, which has persisted historically, despite the fact that the early conceptualization of the wise use of wetlands spoke of the need for a "socio-ecological" approach to wetlands management and governance.

Our analysis of the Convention and its various operating instruments supports this call for a strategic reformulation. However, building on feminist analyses of other natural resources management and governance policies 
and processes, we caution that simply reformulating a socio-ecological approach might not arrest the continued global loss and/or degradation of wetlands (Finlayson 2012). Globally, habitat loss, defaunation, and carbon emissions have spiked despite significant advancements on global environmental agreements, national environmental laws and policies, and even codes of conduct for the private sector (Collard and Dempsey 2020). At this critical juncture, the start of the UN Decade on Ecosystem Restoration, it is worth asking how we got into this situation, and how we will get out of this (ibid).

From a feminist ecological perspective, we argue that while it is important to put into practice a socio-ecological approach to challenge the premise of "wise use" (Kumar et al. 2020), these changes need to take root in an approach that allows asking who sets the agenda for wetlands management and governance, why and how (Elias et al. 2021). More simply put, it is important to assess if and how RC policy obligations, resolutions and guidelines and processes of implementation [will] allow for understanding and addressing inequalities and exclusions, and how these are reproduced and played out not just locally, but in multiple, overlapping scales of wetlands access, use, management and decision-making.

In this paper, we analyse, based on four key informant interviews and an extensive literature review of secondary and grey literature, the RC resolutions and guidelines with a Feminist Political Ecology (FPE) lens. The interviews were used to validate the analysis and better link gaps identified in the literature regarding the Convention's treatment of social inclusion and associated political economies, to the origins, history, and structure of the Convention, including its relationship with member countries and implementation of wise use.

We first examine the Convention, its focus on conservation and how RC guidelines and resolutions interpret the socio-economic dynamics in the "wise use" of wetlands. From there we provide a brief overview of a FPE approach, and then we critically analyse three recent inclusion-relevant $\mathrm{RC}$ resolutions, analysing if these allow understanding and acting on the complexity of structural inequalities. In this analysis we also highlight why the institutional structure of the Convention poses systemic and structural challenges to inclusive wetlands governance. To provide insight on why RC institutions, frameworks, and guidelines must grapple with exclusion and complexity, we provide a glimpse of a typical wetlands community and the ground reality challenges to wise use. In the final section of this article, we discuss how a feminist political lens helps explain that a socio-ecological approach requires much more than just rewording gender inequality and social exclusion in RC policy obligations, resolutions, and guidelines.

\section{Ramsar Convention and the Wise Use of Wetlands}

At the heart of the Convention and its global wetlands ambitions is the concept of "wise use" (Kumar et al. 2020). The authors (ibid) argue that the understanding of wise use, conceptualized initially to also take into account the human dimensions of wetlands use and management (Finlayson et al. 2011), has evolved over time to narrowly focus on maintaining the "ecological character of the wetlands", which currently "provides the frame and heuristics" for wetlands management and governance. Kumar et al. (2020) note, that in RC guidelines and interventions, maintaining the ecological character of wetlands, defined and understood as the "structure and inter-relationships between the biological, chemical and physical components of the wetland" is prioritized, constructing a "human-nature dualism" that is at odds with the foundational philosophy of wise use.

The prioritizing of conservation is evident in the RC's mission and in the fine print of what makes for the obligatory "Three Pillars of the Convention" (Ramsar Secretariat 2014). The Ramsar Secretariat requires all signatory contracting parties, who are various designated departments of national governments, to commit to these Three Pillars. Pillar One requires contracting parties to include wetland conservation considerations in their national land-use, hydrological and river basin plans; contracting parties must also commit to implementing these plans as far as possible; and to establishing nature reserves in wetlands and promote training in the fields of wetland research, management and stewardship. Pillar Two requires signatories to designate at least one wetland area nationally as a Ramsar Site, and to promote its conservation, including reporting on any changes to the ecological character of the site. Pillar Three requires all signatories to agree to consult with other Contracting Parties especially regarding transboundary wetlands, shared water systems, and shared species.

Reading into these obligations and taking note of the fact that the key decision-making and implementing authority of wetlands initiatives are national authorities, we reinterpret Kumar et al's (2020) analysis to note that the flexibility and conceptual vagueness that characterises wetland "wise use" and "ecological character" serves to enable communication with and among contracting parties in situations where consensus is neither desired nor possible. This is understandable given that 170 diversely socio-political national governments are committed to the Convention obligations. This explains why, as Kumar et al. (2020) note, "the meaning of wetland wise use has been interpreted in diverse ways, from sustainable harvest of wetland resources (Osumba et al. 2010), maintaining carrying capacity (Huang and Isobe 2012), diverse stakeholder engagement (Cohen-Shacham et al. 2015), to embedding 
in landscape-scale conservation planning and decisionmaking (Finlayson et al. 2005)".

Given the relevance of the three obligatory agreements, it is understandable why the various Guidelines and Resolutions added to the RC framework over time, including to address inclusion, are peripheral. The Convention's "foundational" focus is conservation, interpreted from an "ecological worldview" (Kumar et al. 2020). Conservation and maintaining the ecological character of designated wetlands are what the Three Pillars specify and what the Contracting Parties agree to, report on, and can be held accountable for.

Solely focusing on conservation, on maintaining the ecological character of the wetlands, and not taking into account complex, dynamic socio-ecological interrelations is deeply problematic. An interesting example of why and how wetlands projects fail was the declaration of the Lake Burdur basin in Turkey as a Ramsar site. Fencing off this "major wintering site for the endangered white-head duck (Oxyura leucocephala) through the implementation of a 'hard park' conservation policy" was only possible "in practice [by] disenfranchising and alienating local people", which ultimately also "did not lead to the effective preservation of the basin" (Adaman et al. 2009; 783). Unfortunately, what happened in Lake Burdur is the norm, rather than an exception.

Feminist researchers point out that when external actors, interventions and policies, with varied interests including conservation, carbon sequestration, endangered species, land, livelihoods (Gururani and Vandergeest 2014) take precedence over local knowledges and needs, including plural, customary rights to diverse wetlands resources, the outcomes are not only socially exclusionary, they also do not benefit the natural resource base (Elias et al. 2021). In Lake Burdur in Turkey, the alienation and ostracisation of local stakeholders undermined self-motivated, community-based management which eventually contributed to the degradation of the lake (Kumar et al. 2020).

In addition to the key actors who constitute the Conference of the Contracting Parties, (i.e., COP) and who are designated national government entities, the Convention also has advisory and supporting institutions. The advisory body which reports to the Contracting Party institutions includes a technical and a communication and oversight panel. The supporting institutions include the Convention Secretariat based in Geneva and five international NGOs, recognized formally as official partners of the Convention. In our discussions with four current and former members of these various advisory and supporting institutions, one thing was clear: the scope for informing and influencing the COP is narrow. What was also evident and an often repeated issue in our conversations, was the distinctly Northern make-up of the members of these various institutions. There is no formal representation of any grassroots Southern institutions in the Convention. There has been significant effort to enable gender balance in the Ramsar Secretariat, now headed by a female Secretary General. Unfortunately, this is not mandatory for the other bodies of the RC. Further, as we discuss below, a gender-balanced Ramsar Secretariat has not translated to more inclusive and gender transformative approaches and guidelines or socially informed interpretations of wise use.

\section{A Feminist Political Ecology Critique of the RC: Resolutions, Guidelines and Interventions}

Before we begin to analyse the structure and culture of the Ramsar Convention, it is important to briefly explain what constitutes a Feminist Political Ecology (FPE) perspective. Feminist political ecology goes well beyond bringing on board women in essentially masculine institutional spaces or the engaging of [assumedly homogenous] women in community level interventions. The latter is explained often through simplistic, apolitical framing of women-naturenurture relationships, i.e., where women are often assumed due to their traditional gender roles to be closer to nature, therefore have a desire to protect it (Mies and Shiva 1993). FPE approaches explain how gender, in relation to class, race, and other relevant axes of power, shapes access to and control over natural resources; how these axes of power are situated in intertwined histories of colonialism, patriarchy, and capitalism - and how these put together impacts, who counts as a knowledge producer, what counts as knowledge and how knowledge is produced (Sundberg 2017).

Nancy Fraser (1997) argued that without a broader conceptualization of justice, i.e., attention to the combined impacts of economic, political, ecological and cultural injustices, 'gender equality' cannot be guaranteed in environmental interventions. According to her, to closely understand the gendered dimensions of nature-society interrelations, one needs to understand power relations, which are embedded in specific historical, spatial, and socio-political contexts.

When we closely analyse the RC-both its institutional structure, as well as its various objectives and ambitionswhat is most striking, is that the RC in its design, execution, and evaluation relies heavily on external and mostly Northern actors, who are essentially distinct from local wetlands users, (i.e., heterogeneous local communities). The RC relies on the COP, its key national government partners to deliver, implement, and regulate conservation. Achieving the commitment and agreement of 170 national governments is indeed commendable. Nonetheless, it does not preclude the reality that in many instances, national governments are themselves, key drivers of ecological degradation. There is also the issue of which national entities are represented in the COP. In our discussions, we understood these to be mostly technical departments whose key agenda is biophysical conservation. 
Regardless of their role, the supporting and advisory institutions, including the Ramsar Secretariat, are often unable to hold national governments accountable to sustainable, leave alone, inclusive wetlands governance. The point we raise here is that in some [not all] socio-political contexts, this function is achieved and the mandate of local civil society actors, people's grassroots movements.

One could conversely argue that these gaps are addressed by the increasing intent by the RC to engage local communities in wetlands management and governance. However, it has been noted that the resolutions and guidelines do not provide robust insight on the diversity of local wetlands users (Wood 2003, Gujja 1998), and more specifically how intersectional inequalities, such as gender, class, ethnicity or other disparities make some among local communities more vulnerable and excluded (Wongthong and True 2015). It is unsurprising that the complexity of social, political and economic inequalities and power imbalances, which lie at the heart of nature-society interrelations, are poorly considered in wetlands management and governance.

We mentioned above that the key obligatory agreements are as noted in the Three Pillars. RC Resolutions and Guidelines are therefore essentially, as the terminology suggests, guiding documents. In other words, these are non-binding recommendations. Nonetheless, in this section, we take a close look at three RC Resolutions which we identify as key to inclusion. This includes the resolution to align wise use with indigenous cultures, visions, and values (Resolution VIII.19, 2002), to eradicate poverty (Resolution XI.13, 2012), and address gender equality (Resolution XIII.18, 2018).

Resolution VIII.19, while giving importance to the cultural aspects of wetlands, lends to the popular assumption that special groups, (i.e., indigenous peoples) cultures are determined through their use of wetlands. Closely associating indigenous culture with sustainable wetlands management helps further the conservation agenda. For example, how indigenous groups in Australia "voluntarily manage" their territory for biodiversity and cultural conservation (Ramsar Convention 2018b). This assumption aside, there is limited follow up guidance to policy, decision-makers, and practitioners on how to ensure that the culture, voice, and needs of indigenous groups inform and shape the wise use of wetlands. What is most important is that there is little attention to culture and indigeneity in the setting of conservation agendas, which is squarely determined by the focus on conservation.

On gender, Bastian et al. (2016) reporting on behalf of the International Union for Conservation of Nature's (IUCN) Global Gender Office (GGO), note that gender equality is neither widely written into policy nor widely measured. Where there is mention of gender, the term, as discussed above, is a proxy for women, with women being characterized as stakeholders excluded from access to decision-making arenas and as beneficiaries of development programmes (ibid).

RC resolutions and guidelines interpret "gender" as "women", and separately categorize women and indigenous populations as vulnerable and yet capable actors to take on environmental stewardship. The paradoxical framing of vulnerability and capability corresponds to an economic framing of restoration-situations of win-win-win between ecosystem restoration and (women's) participation. The fact that conservation initiatives can lead to the exclusion (as discussed above in the Turkey case) or can add to women's work burdens is hardly considered. How women and other supposedly vulnerable groups will navigate formal and informal spaces of wetlands management and governance, from the household up to national secretariats (Kabeer 1994) is poorly understood and addressed in the framing of the RC resolutions. The overtly technocratic focus emphasizes "fitting in women" into restoration agendas predetermined by expert others (Jackson 1997). A Feminist Political Ecology perspective informs that gender is not about how to engage women and neither is inclusion about integrating other assumedly homogeneous groups of the vulnerable in restoration initiatives (Elias et al. 2020).

Resolution XI.13 recognizes poverty as a multidimensional and complex phenomenon, and acknowledges that poverty (especially rural poverty), makes certain sections of communities disproportionately dependent on local ecosystems. Situating poverty as a driver of wetlands overexploitation helps further the argument that putting an economic value to nature and natural resources serves to ensure conservation and equity. However, this reasoning does not explain how conservation can tackle or reverse the inequalities that shape nature-society interrelations (Agarwal 1994, Jackson 1993, Leach et al. 2007). Poverty can indeed be a driver of wetland over-exploitation, but without alluding to the power and politics of how access to, use, and control of wetlands resources are determined, the link drawn between poverty and the wise use of wetlands management becomes overly simplistic. Resolution XI.13 states that the failure to follow wise use principles can exacerbate the problem by pushing people into poverty (Ramsar Convention Secretariat 2012). This might indeed be true, but the converse of this statement does not always hold good. That is, the wise use of wetlands determined through principles of economic efficiency will not necessarily reduce poverty (Carney 1993).

Sellamuttu et al. (2012) emphasize that key to managing wetlands sustainably is to implement wise use on the ground through the effective engagement of local communities and by ensuring equity and transparency when making trade-offs between wetland users. However, evidence from outside the wetlands domain shows that without acting on the structural barriers to gendered inequalities, it is problematic to assume that strategic alliances and collective action in relation to natural resource 
access and use can be established between diverse groups of men and women, within and between households (de la Torre-Castro 2019, Harrison and Watson 2012, MathezStiefel et al. 2016, Rao 2017, Ravera et al. 2016, Rist et al. 2007). Strategies for mitigating change, particularly conservation and adaptation, often reinforce structures and systems of exclusion (Kaijser and Kronsell 2014) when they do not coherently reflect underlying and implicit power patterns locally and at scale (Winker and Degele 2011). In the consideration of trade-offs between wetland uses and users it is often overlooked that such trade-offs tend to be unequal, with the "costs", which are not just economic, being borne disproportionately by the most marginalized amongst local communities.

An inclusive socio-ecological approach requires intentionally strengthening, creating, or shifting structures, practices, relations, and dynamics toward equality (McDougall et al. in press). Without considering how intersecting inequalities at scale impact recognition, especially the ability to shape restoration agendas, restoration initiatives will never be truly transformative.

Allendorf et al. (2006) have noted that the lack of robust tools that can identify and take account of plural rights in dynamically evolving local contexts will disallow truly participatory processes which are fundamental to the wise use of wetlands. Similarly, Kumar et al. (2020; C) argue that "a reframing of ... wise use can enable a broader societal engagement on the state of wetlands and allow the inclusion of diverse knowledge systems to help structure and nurture meaningful dialogues". We agree, but only partially with these recommendations. Inclusive policies, guidelines, recommendations, and tools are essential, but there is little evidence that the right policies or tools will result in transformative change processes. Feminist researchers argue that the problems of "commons management" are not simply "local" problems (Clement et al. 2019). Wider economic, social, and political contexts shape environmental changes and challenges in different ways, including in determining voice, representation and agency in various institutional spaces such as the household, community, and beyond. A truly socio-ecological process will require grappling with the complexity of these matrices of inequalities and an essential starting point is critically analyzing who sets the agenda of the wise use of wetlands resources and landscapes, and why and how.

RC policy obligations, resolutions, and guidelines, including the recent Global Wetland Outlook report (Gardner and Finlayson 2018), position local communities as homogeneous, or neatly segregated by gender, poverty and indigeneity. In the section below, we highlight why reformulating the wetlands approach, adding in a socioecological approach will not necessarily address these critical gaps. Moreover, revising and rewording RC resolutions and guidelines will not in themselves restructure exclusionary cultures and processes of decision-making across what makes for the Ramsar Convention institutional landscape.

In sum, a socio-ecological approach that enables inclusive wetlands management and governance will need to go beyond fitting in predetermined groups of the marginalized-women, indigenous communities and now increasingly, youth -into restoration and conservation agendas. In reimagining wise use, the focus on restoration and conservation will need to be more strategically informed by the plural voices, values and situated knowledges around [degraded] landscapes, and enable these voices to hold accountable wetlands management and governance. Complementing the call for a reformulation of wise use and the revision of wetlands policy obligations, resolutions, and guidelines, we call for a systemic and structural change in the RC institutional structures and processes. At the start of the UN Decade for Ecosystem Restoration, these shifts are strategic to aligning with the 2030 transformative agenda.

\section{Rethinking the Ramsar Convention: Why Going beyond Words and Approaches Matter}

It is both necessary and important to add here, that our interest in working towards more inclusive and equitable RC guidelines is informed by our engagement in wetlands management interventions. The co-authors are an interdisciplinary group of researchers currently engaged in informing and ensuring that an ongoing wetlands management project in Myanmar adopts a socially inclusive and gender transformative approach. The focus in this paper is not to discuss this project or its implementation; however, it is useful to provide a glimpse of ground realities, to provide perspective on why there is a critical need for more sophisticated approaches, tools, and methods to tackle intersectional inequalities and deep-rooted gender norms, which exist at scale in wetlands landscapes.

In 2019, a significantly large group of us, including the project implementation team visited one such remote, rural, estuarine wetlands village. We were mostly foreigners, most of us did not speak the local dialect/s and aided by two local language speaking translators we tried to make sense of the power dynamics in the village community. Although there was much curiosity both on our end, as well as by the local community, the translated conversations did not reveal much. We could however make some sense of power dynamics in who sat where, who spoke and did not. As the meeting ended, we tried to engage smaller groups in separate side conversations. From these meetings, we learned that recently, embankments had been constructed through official funds to convert a stretch of the backwater lakes into paddy fields, which were allocated to a select group of households. The allocation of these newly constructed fields had not been transparent. The village head had unilaterally decided and his authority was not 
challenged, even though there was obvious resentment. It appeared that a small number of relatively privileged men hold political roles in these locations.

Breaking away from our conversations, we walked along the newly constructed embankment bunds where a few women and men, who had been sitting in the periphery in the meeting place, silent throughout our discussions with the "community", kept walking alongside us. One of us in the group spoke a local dialect, and it was soon clear that this group of local community wanted to have a conversation separately, far away from the meeting place and the main village. Our discussions with this group revealed that deep disparities along ethnicity and religious divides fracture what makes for the local community. None of this group had been able to gain access the to the paddy land that had become newly available through the construction of an embankment. However, their key concerns were not about equitable access to resources and decision-making locally since they knew this would be quite challenging. They were more concerned with the lack of opportunities, as well as resources for their children to migrate to urban areas or abroad to alternative livelihoods. Unfortunately, due to administrative constraints in obtaining the National Identity Card, given the group's ethnicity, only illegal, precarious livelihood options are available to many of these youth, including in neighbouring Thailand. The opening of the Myanmar economy had resulted in many new opportunities for rural youth, but that experience had clearly not been equal. It was very evident that inequality here was deeply intersectional and complex, determined by historic events of colonialism and capitalism that had resulted in the forced relocation of people across countries, then under the British Empire.

This glimpse of what makes for a local village community raises many questions of the win-win strategies outlined in the project goals, which are informed by RC guidelines. The project's aim is sustainable long-term management of coastal natural resources to conserve their unique biodiversity while benefiting local communities that depend on them through co-management between communities, government, and other institutions, including the private sector. A key focus of the project is to improve livelihood security of vulnerable women and men in the region. In project documents, this is best achieved through fisheries value chain development. Unfortunately, in this location the resource base for this livelihood, the common pool inland fishing grounds, were already diminishing from the recent conversion to privately parcelled paddy fields. The project focus on expanding inland fisheries in the village is also at odds with the reality that rice (or paddy) has uniquely shaped Myanmar's economic and political history and continues to shape agrarian reforms and development in the country (Nehru 2015). In Myanmar, the State has historically enabled "favoured individuals or groups" to expand paddy cultivation, in the process making the most marginalised "extremely vulnerable to food insecurity and forced displacement" (Srinivas and Hlaing 2015). In sum, power and politics at scale are key deterrents to the project's vision of the wise use of wetlands, and yet there is little in RC guidelines and resolutions that explain how these differences are to be identified and tackled.

To have a chance of realizing its goal of wise use, the project will need to capture the politics of deep-rooted inequalities, including how relationships of power are reinforced between local government and community members (Akbulut 2012). In our minds this single visit to a wetlands village raised many questions on whether and how the project would unpack complex, contextual power balances and intervene to address entrenched inequalities. As mentioned above, we do not intend to further discuss the project; however, we note that to this project's credit, supporting the work of the authors in the wetland indicates its acknowledgement of the need for a deeper social analysis that can enhance its social engagement strategies.

\section{Conclusion}

RC policy instruments, the policy obligations outlined in the Three Pillars, and the RC's various Resolutions and Guidelines provide an important starting place for promoting and guiding stakeholder-driven management, for providing directions in navigating various institutional landscapes, and for the review of ground level interventions and outcomes (Ramsar Convention Secretariat 1993, 2010a, 2010b). The translation of these instruments into desired socio-ecological outcomes requires truly participatory decision-making processes, but in fact, the reality is mostly asymmetric access to information and uneven constraints and incentives to participation (Akbulut 2012).

Inclusive wetlands conservation is not possible without a core focus on the historical context of deep-rooted social, political, and economic disparities. Despite the intentions of the RC and the coining of the term wise use, its history originally concerned with water bird conservation, and trajectory has been heavily influenced by external, mostly Northern biophysical scientists, conservationists, and [male] representatives from technical national government institutions. This has resulted in a top-down, technocratic vision and meaning of the wise use framework, which focuses on implementation and management through governmental agencies. Our analysis points first and foremost to the need to achieve a greater inter-disciplinarity in the RC scientific community. This diversity of perspectives and knowledges will enrich the wise use discourse, offering the potential to bring to greater prominence other knowledge, especially traditional ecological knowledge, which so far has had a limited role in a knowledge space dominated by modern physical sciences. For all these reasons and for enhancing accountability to local wetlands user 
communities, we argue for a formal Southern grassroots presence in the RC.

Secondly, a Feminist Political Ecology approach informs that participatory processes of management and governance requires considering that access, use, and control of natural resources are "steeped in colonial modalities of power and propped up by imperial geopolitical and economic arrangements" (Maldonado Torres 2007 in Collard et al. 2015; 2). Fraser (1997) has argued that equality, including gender equality cannot be guaranteed in environmental interventions without attention to inequalities in nested, polycentric, decision-making spaces. Especially in situations of change and uncertainty, because of climate and other dynamically evolving economic and political factors, it is wiser to recognize the complexity of intersectional power imbalances in wetlands resource use, access, and decision-making at scale and plan for iterative management interventions, rather than assume universal synergistic win-win-win solutions (Cleaver and Whaley 2018).

A FPE approach calls for paying attention to the matrix of "vertical inequalities" (Stewart 2002) such as political, economic, and ecological disparities, and "horizontal inequalities" such as gender, class, religion, age and ethnicity (Kabeer 2015) in understanding structures and systems of exclusion. Such approaches, deployed at decision-making, planning, and implementation levels, at multiple scales (miso, micro, and macro) can influence power structures and personal and cultural norms in wetlands governance.

External projects operating under the umbrella of the $\mathrm{RC}$ are likely to rely on policy instruments, guidelines, and tools, outlined in the RC portfolio, to achieve the goal of conservation and maintenance of the ecological character of the wetlands. We emphasize here that feminist approaches caution against prescriptive tools and methods. The issue is not about how to technically fix wetlands management and governance, it is essentially about the need to critically reflect on, and rethink who decides, how and why-what makes for the wise use of wetlands.

Pursuing a narrow ecological goal and assuming this can be offset through simplistic economic trade-offs makes for a problematic assumption and is also difficult to guarantee. This is because, on the one hand, in "situations of increasing variability and unpredictably of ecological processes, surprise rather than predictability is the norm" (Scheffer 2009 in Kumar et al. 2020; B). Additionally, it is not just ecological processes that are dynamically evolving, this is true also of political and economic contexts.

The above considerations show that many variables and disparities at scale must be understood and tackled in the structural re-thinking of how wetlands are conceived, managed and governed. This raises many questions on the current design of individual projects, especially in whether they enable tackling entrenched vertical and horizontal power centres and structures. In this context, a FPE approach, which calls for a more nuanced understanding of complexity at hand will significantly enrich the understanding, framing and effectiveness of wise use. Our analysis raises more challenges than solutions, but this is the point we want to make here. It is now time to envision alternate modalities if we are to end persisting wetlands degradation.

\section{Acknowledgments}

The authors wish to acknowledge the following for sharing, as Key Informants, their vast knowledge on wetlands wise use and the evolution and functioning of the Ramsar Convention, given their long associations with the Convention: Dr. Max Finlayson, Adjunct Professor, Institute for Land, Water and Society, Charles Sturt University, Australia and Ramsar Chair for the Wise Use of Wetlands, IHE Delft, Institute for Water Education, Netherlands; Dr. Nick Davidson, Principal, Nick Davidson Environmental, UK and Adjunct Professor, Institute for Land, Water and Society, Charles Sturt University, Australia; Dr. Ritesh Kumar, Director, Wetlands International South Asia and Robert McInnes, Director, RM Wetlands \& Environment Ltd and Adjunct Professor, Institute for Land, Water and Society, Charles Sturt University, Australia. Conversations with these Key Informants enabled the authors to better link gaps identified in the paper regarding the Convention's treatment of social inclusion and associated political economies, to the origins, history and structure of the Convention, including its relationship with member countries.

\section{References}

Adaman, F., S. Hakyemez and B. Ozkaynak. 2009. The political ecology of a Ramsar site conservation failure: The case of Burdur Lake, Turkey. Environment and Planning C: Government and Policy 27. doi:783-800. 10.1068/c0840.

Agarwal, B. 1994. A Field of One's Own: Gender and Land Rights in South Asia. Cambridge South Asian studies (USA).

Akbulut, B. 2012. Community-Based Resource Management in Turkey: 'Je Participe, Tu Participes, Il Participe... Ils Profitent'1. Development and Change, 43:1133-1158.

Allendorf, T., K. Khaing Swe, T. OO, Y. Htut, M. Aung, M. Aung, et al. 2006. Community attitudes toward three protected areas in Upper Myanmar (Burma). Environmental Conservation 33: 344-352.

Bastian, L., M. Gilligan and B. Clabots. 2016. Gender and Protected Areas: Exploring National Reporting to the Ramsar Convention and the World Heritage Convention. Washington, DC: IUCN Global Gender office.

Carney, J. 1993. Converting the wetlands, engendering the environment: The intersection of gender with agrarian change in the Gambia. Economic Geography 69:329-348.

Cleaver, F. and L. Whaley. 2018. Understanding process, power, and meaning in adaptive governance: A critical institutional reading. Ecology and Society 23:49.

Clement, F., W.J. Harcourt, D. Joshi and C. Sato. 2019. Feminist Political Ecologies of the Commons and Commoning. International Journal of the Commons 13:1-15.

Cohen-Shacham, E., T. Dayan, R. de Groot, C. Beltrame, F. Guillet and E. Feitelson. 2015. Using the ecosystem services concept to analyse stakeholder involvement in wetland management. Wetlands Ecology and Management 23:241-256. 
Collard, R.C. and J. Dempsey. 2020. Two icebergs: Difference in feminist political economy. Environment and Planning A: Economy and Space 52:237-247.

Collard, R.C., J. Dempsey and J. Sundberg. 2015. A manifesto for abundant futures. Annals of the Association of American Geographers 105.2:322-330.

de la Torre-Castro, M. 2019. Inclusive Management through Gender Consideration in Small-Scale Fisheries: The Why and the How. Frontiers in Marine Science 6:1-11.

Elias, M., D. Joshi and R. Meinzen-Dick. 2021. Restoration for whom, by whom? Exploring the socio-political dimensions of restoration. Ecological Restoration 39:3-15.

Elias, M., B. Sijapati Basnett and J. Dey de Pryck. 2020. Tackling Gender Inequality through Forest-Related Policies and Programmes. Pages 167-196 in William Nikolakis and John Innes (eds.), The Wicked Problem of Forest Policy: A Multidisciplinary Approach to Sustainability in Forest Landscapes. Cambridge, England: Cambridge University Press.

Finlayson, C.M. 2012. Forty years of wetland conservation and wise use. Aquatic Conservation: Marine and Freshwater Ecosystems 22:139-143

Finlayson, C.M., M.G. Bellio and J.B. Lowry. 2005. A conceptual basis for the wise use of wetlands in northern Australia: linking information needs, integrated analyses, drivers of change and human well-being. Marine and Freshwater Research 56: 269-277.

Finlayson, C.M., N. Davidson, D. Pritchard, G.R. Milton and H. MacKay. 2011. The Ramsar Convention and ecosystembased approaches to the wise use and sustainable development of wetlands. Journal of International Wildlife Law \& Policy 14.3-4:176-198.

Fraser, N. 1997. Justice Interruptus: Critical Reflections on the "Postsocialist" Condition. NY, NY: Routledge.

Gardner, R.C. and M. Finlayson. 2018. Global wetland outlook: State of the world's wetlands and their services to people 2018. Secretariat of the Ramsar Convention.

Gujja, B. 1998. Wetlands: who can use them wisely? Paper presented at the Second International Conference on Wetlands and Development, 8-14 November, Dakar, Senegal.

Gururani, S. and P. Vandergeest. 2014. Introduction: New Frontiers of Ecological Knowledge: Co-producing Knowledge and Governance in Asia. Conservation and Society 12:343-359.

Harrison, E.A. and E.E. Watson. 2012. Mind the Gap: Disciplinary Dissonance, Gender, and the Environment. Society \& Natural Resources: An International Journal 25:933-944.

Huang, G. and M. Isobe. 2012. Carrying capacity of wetlands for massive migratory waterfowl. Hydrobiologia 697:5-14.

Jackson, C. 1993. Doing what comes naturally? Women and environment in development. World Development 21:1947-1963.

Jackson, C. 1997. Sustainable development at the sharp end: fieldworker agency in a participatory project. Development in Practice: an Oxfam Journal (United Kingdom).

Kabeer, N. 1994. Reversed realities: Gender Hierarchies in Development Thought. London, UK: Verso.

Kabeer, N. 2015. Gender, poverty, and inequality: A brief history of feminist contributions in the field of international development. Gender \& Development 23:189-205.

Kaijser, A. and A. Kronsell. 2014. Climate change through the lens of intersectionality. Environmental Politics 23:417-433.

Kumar, R., R. McInnes, C.M. Finlayson, N. Davidson, D. Rissik, S. Paul et al. 2020. Wetland ecological character and wise use: Towards a new framing. Marine and Freshwater Research A-E. doi.org/10.1071/MF20244.
Leach, M., G. Bloom, A. Ely, P. Nightingale, I. Scoones, E. Shah and A. Smith. 2007. Understanding Governance: pathways to sustainability. STEPS Working Paper 2, Brighton: STEPS Centre.

Maldonado-Torres, N. 2007. On the coloniality of being. Cultural Studies 21:240-70, in Collard, R.C., J. Dempsey and J. Sundberg. 2015. A manifesto for abundant futures. Annals of the Association of American Geographers 105:322-330.

Mathez-Stiefel, S., J. Ayquipa-Valenzuela, R. Corrales-Quispe, L. Rosales-Richard and M. Valdivia-Díaz. 2016. Identifying Gender-Sensitive Agroforestry Options: Methodological Considerations from the Field. Mountain Research and Development 36:417-430.

McDougall, C., L. Badstue, M. Elias, G. Fischer, D. Joshi, R. Pyburn, A. Mulema, D. Majjar and V. Voss. In press. Beyond Gender and Development: How gender transformative approaches in agriculture and natural resource management can advance equality. In CGIAR Collaborative Platform for Gender Research Book 2021, CGIAR Gender Platform.

Mies, M. and V. Shiva. 1993. Ecofeminism. Halifax, Nova Scotia: Fernwood Publications.

Nehru, V. 2015. The Political Economy of Reform in Myanmar: The Case of Rice and the Need for Patience. Sasakawa Peace Foundation, USA.

Osumba, J.J.L., J.B. Okeyo-Owuor and P.O. Raburu. 2010. Effect of harvesting on temporal papyrus (Cyperus papyrus) biomass regeneration potential among swamps in Winam Gulf wetlands of Lake Victoria Basin, Kenya. Wetlands Ecology and Management 18:333-341.

Ramsar Convention Secretariat. 1993. Additional Guidance for the Implementation of the Wise Use Concept, Japan: Meeting Proceedings.

Ramsar Convention Secretariat. 2010a. Wise use of wetlands: Concepts and approaches for the wise use of wetlands. Ramsar handbooks for the wise use of wetlands. Switzerland: Ramsar Convention Secretariat. 4.1.

Ramsar Convention Secretariat. 2010b. Participatory skills: Establishing and strengthening local communities' and indigenous people's participation in the management of wetlands. Ramsar handbooks for the wise use of wetlands. Switzerland: Ramsar Convention Secretariat. 4.7.

Ramsar Convention Secretariat. 2012. Resolution XI.9 An Integrated Framework and guidelines for avoiding, mitigating and compensating for wetland losses. Romania: Meeting Proceedings.

Ramsar Convention Secretariat. 2014. Wise use of wetlands: Concepts and approaches for the wise use of wetlands. Ramsar Handbooks for the Wise Use of Wetlands. Switzerland: Ramsar Convention Secretariat 4.1.

Ramsar Convention Secretariat. 2018a. Resolution XIII.18 Gender and Wetlands. United Arab Emirates: Meeting Proceedings.

Ramsar Convention Secretariat. 2018b. Global Wetland Outlook: State of the World's Wetlands and their Services to People. Gland, Switzerland: Ramsar Convention Secretariat.

Ramsar Convention Secretariat. 2018c. Resolution XII.15: Cultural Values and Practices of Indigenous Peoples and Local Communities and Their Contribution to Climate-Change Mitigation and Adaptation in Wetlands. UAE: Meeting Proceedings.

Rao, N. 2017. Assets, Agency and Legitimacy: Towards a Relational Understanding of Gender Equality Policy and Practice. World Development 95:43-54.

Ravera, F., I. Iniesta-Arandia, B. Martín-López, U. Pascual and P. Bose. 2016. Gender Perspectives in Resilience, Vulnerability 
and Adaptation to Global Environmental Change. Ambio 45: 235-247.

Rist, S., M. Chidambaranathan, C. Escobar, U. Wiesmann and A. Zimmermann. 2007. Moving from Sustainable Management to Sustainable Governance of Natural Resources: The Role of Social Learning Processes in Rural India, Bolivia and Mali. Journal of Rural Studies 23:23-37.

Scheffer, M. 2009. Critical Transitions in Nature and Society. Princeton, NJ: Princeton University Press.

Sellamuttu, S., S. de Silva, N. Nagabhatla, C. Finlayson, C. Pattanaik and N. Prasad. 2012. The Ramsar Convention's Wise Use Concept in Theory and Practice: An Inter-Disciplinary Investigation of Practice in Kolleru Lake, India. Journal of International Wildlife Law \& Policy 15:228-250.

Srinivas, S. and U.S. Hlaing. 2015. Myanmar: Land Tenure Issues and the Impact on Rural Development. Myanmar: National Action Plan for Agriculture (NAPA). Yangon, Myanmar. Food and Agriculture Organization of the United Nations.

Stewart, F. 2002. Horizontal Inequalities: A Neglected Dimension of Development. QEH Working Papers, Queen Elizabeth House, University of Oxford.

Sundberg, J. 2017. Feminist Political Ecology. International Encyclopedia of Geography: People, the Earth. Environment and Technology. Wiley Online Library.

Winker, G. and N. Degele. 2011. Intersectionality as multi-level analysis: dealing with social inequality. European Journal of Women's Studies 18:51-66.

Wongthong, P. and J. True. 2015. Community-Led Coastal Management in the Gulf of Mottama Project (CLCMGoMP) Updated situation analysis of the Gulf of Mottama Based on the rapid socio-ecological assessment. Swiss Agency for Development and Cooperation 1-35.

Wood, A. 2003. Wetlands, gender and poverty some elements in the development of sustainable and equitable wetland management.
In Abebe, Y.D. and Geheb, K. (eds), Wetlands of Ethiopia. Proceedings of a seminar on the resources and status of Ethiopia's wetlands. Nairobi, Kenya: IUCN-The World Conservation Union, Wetlands and Water Resources Programme IUCN, Regional Office for Eastern Africa.

Deepa Joshi, International Water Management Institute and Water, Land and Ecosystems, Colombo, Western Province, Sri Lanka.

Bryce Gallant (corresponding author) International Water Management Institute and Water, Land and Ecosystems, 1138 McCalman Ave, Winnipeg, MB, Canada, R2L 1H9, b.gallant@cigar.org.

Arunima Hakhu, International Water Management Institute and Water, Land and Ecosystems, New Delhi, Delhi, India.

Sanjiv De Silva, International Water Management Institute, Colombo, Western Province, Sri Lanka.

Cynthia McDougall, WorldFish, Bayan Lepas, Penang, Malaysia.

Mark Dubois, WorldFish, Yangon, Myanmar.

Indika Arulingam, International Water Management Institute, Colombo, Western Province, Sri Lanka. 